\title{
Feeding Preterm Infants after Hospital Discharge: Growth and Development at 18 Months of Age
}

\author{
RICHARD J. COOKE, NICK D. EMBLETON, IAN J. GRIFFIN, JOHN C. WELLS, \\ AND KENNY P. MCCORMICK \\ Special Care Baby Unit, Royal Victoria Infirmary, Newcastle Upon Tyne, United Kingdom [R.J.C., \\ N.D.E., I.J.G., K.P.M.]; and Nutrition Department, Nutricia Ltd., Trowbridge, Wiltshire, United Kingdom \\ [J.C.W.]
}

\begin{abstract}
ABST
We have shown that preterm infants fed a preterm formula
grow better than those fed a standard term infant formula after
hospital discharge. The purpose of this follow-up study was to
determine whether improved early growth was associated with
later growth and development. Preterm infants ( $1750 \mathrm{~g}$ birth
weight, $\leq 34$ wk gestation) were randomized to be fed either a
preterm infant formula (discharge to 6 mo corrected age), or a
term formula (discharge to 6 mo), or the preterm (discharge to
term) and the term formula (term to 6 mo). Anthropometry was
performed at 12 wk and 6,12 , and 18 mo. Mental and psychomo-
tor development were assessed using the Bayley Scales of Infant
Development II at 18 mo. Differences in growth observed at 12
wk were maintained at 18 mo. At 18 mo, boys fed the preterm
formula were $1.0 \mathrm{~kg}$ heavier, 2 cm longer, and had a $1.0 \mathrm{~cm}$
greater occipitofrontal circumference than boys fed the term
formula. Boys fed the preterm formula were also $600 \mathrm{~g}$ heavier
and 2 cm longer than girls fed the preterm formula. However, no
\end{abstract}
differences were noted in MDI or PDI between boys fed the preterm formula and boys fed the term formula or between the boys fed preterm formula and girls fed the preterm formula. Overall, boys had significantly lower MDI than girls (mean difference, 6.0; $p<0.01$ ), primarily reflecting lower scores in boys fed the term formula. Thus, early diet has long-term effects on growth but not development at 18 mo of age. Sex remains an important confounding variable when assessing growth and developmental outcome in these high-risk infants. (Pediatr Res 49: 719-722, 2001)
PDI, psychomotor development index using the Bayley Scales of Infant Development II
MDI, mental development index using the Bayley Scales of Infant Development II
OFC, occipitofrontal circumference

Considerable attention has focused on the relationship between diet, growth, and development in preterm infants. Inadequate dietary intake has been related to poorer growth (1-9). It has, therefore, been suggested that appropriate and timely dietary intervention will not only improve growth but also development in these high-risk infants (10-14).

Examining the effects of diet, we have shown that preterm infant boys fed a preterm formula between hospital discharge and 6 mo corrected age not only have increased body weight but also increased linear and head growth when compared with boys fed a term formula or girls fed a preterm formula $(15,16)$. It was, therefore, hypothesized that improved early growth would be associated with better later growth and development at 18 mo corrected age.

Received August 30, 2000; accepted December 21, 2000.

Correspondence and reprint requests: R.J. Cooke, M.D., FRCPI, FRCPCH, FAAP, Ward 35, Leazes Wing, Royal Victoria Infirmary, Newcastle Upon Tyne, United Kingdom NE1 4LP; e-mail: R.J.Cooke@ncl.ac.uk

Supported by a grant from Nutricia Ltd., Trowbridge, Wilts, United Kingdom.

\section{METHODS}

This study was prospective, blinded, randomized, and controlled. Infants were recruited from a single center, i.e. Special Care Baby Unit, Royal Victoria Infirmary, Newcastle upon Tyne, UK. The study began immediately before initial hospital discharge and lasted until 18 mo corrected age. The study was approved by the Ethics Committee of the Newcastle and North Tyneside Health Authority. Informed consent was obtained from the parent(s) or legal guardian.

The details of the study have been already published (15, 16). Otherwise normal preterm infants ( $\leq 1750 \mathrm{~g}$ birth weight, $\leq 34$ wk gestation) were randomized to be fed a preterm infant formula from discharge to 6 mo corrected age (A), a term formula from discharge to $6 \mathrm{mo}(\mathrm{B})$, or the preterm formula (discharge to term) and then the term formula (term to $6 \mathrm{mo} ; \mathrm{C}$ ) at hospital discharge.

The composition of the study formulas is presented in Table 1. The preterm formula differed in several respects from the term formula; e.g. energy, protein, mineral. Ready-to-feed formula was provided in cartons containing $24 \times 100-\mathrm{mL}$ 
Table 1. Composition of study formulas (per $100 \mathrm{~mL}$ )

\begin{tabular}{lcc}
\hline Composition & Term formula & Preterm formula \\
\hline Protein $(\mathrm{g})$ & 1.4 & 2.2 \\
Casein & 0.6 & 0.9 \\
Whey & 0.8 & 1.3 \\
Fat $(\mathrm{g})$ & 3.6 & 4.4 \\
Vegetable oil & $95 \%$ & $95 \%$ \\
Milk fat & $5 \%$ & $5 \%$ \\
Carbohydrate $(\mathrm{g})$ & 7.5 & 8.5 \\
Energy (kcals) & 66 & 80 \\
Minerals $(\mathbf{m g})$ & & \\
Calcium & 54 & 108 \\
Phosphorus & 27 & 54 \\
Magnesium & 5 & 8 \\
Sodium & 18 & 32 \\
Potassium & 65 & 71 \\
Iron & 0.5 & 0.9 \\
Zinc & 0.4 & 0.7 \\
Vitamins $(\boldsymbol{\mu g})$ & & \\
Retinol & 80 & 100 \\
Cholecalciferol & 1.1 & 2.4 \\
dL-alpha-tocopherol & 1.1 & 1.4 \\
\hline
\end{tabular}

bottles. None of the formulas were supplemented with longchain polyunsaturated fatty acids.

During the study, infants were seen at $12 \mathrm{wk}$ and at 6,12 , and 18 mo corrected age. Regular telephone contact was maintained between visits. Timing and the nature of the weaning diet were entirely at the discretion of the parent(s) or guardian(s). Weight, length, and head circumference determinations were performed at each visit. Bayley MDI and PDI assessments were performed at 18 mo by one of two pediatricians (K.M.C., N.E.), specially trained for the purpose and blinded to the type of dietary intervention.

Data were expressed in absolute terms and as SD scores using the British 1990 growth reference standards (17) and were analyzed using ANOVA, with group and sex as blocking variables. Post hoc comparisons were determined using Fisher's protected least significant difference test. Results were considered significant at $p<0.05$.

\section{RESULTS}

The birth characteristics of the study infants are presented in Table 2. No significant differences were detected in birth weight or gestational age among the groups. In boys and girls, no significant differences were detected in weight gain, length gain, or OFC gain between $12 \mathrm{wk}$ and 18 mo among the treatment groups.

Table 2. Characteristics of the study infants

\begin{tabular}{cccc}
\hline Characteristic & A & B & C \\
\hline Birth weight $(\mathrm{g})$ & & & \\
Boys $(n=52)$ & $1396 \pm 307$ & $1498 \pm 336$ & $1288 \pm 350$ \\
$\quad$ Girls $(n=61)$ & $1420 \pm 337$ & $1277 \pm 282$ & $1358 \pm 301$ \\
Gestation (wk) & & & \\
Boys & $30.7 \pm 2.4$ & $31.8 \pm 2.4$ & $30.5 \pm 2.1$ \\
Girls & $31.3 \pm 2.2$ & $30.1 \pm 2.1$ & $31.0 \pm 2.1$ \\
\hline
\end{tabular}

Values are reported as mean \pm SD. A, B, and C represent infants fed the preterm formula, the term formula, and the preterm + the term formula, respectively.
The growth data of the study infants are presented in Figure 1. In boys, weight, length, and OFC were greater in group A than groups $\mathrm{B}$ and $\mathrm{C}(p<0.0001)$. At $18 \mathrm{mo}$, boys in group A remained heavier $(10.7 \pm 1.5 \mathrm{~kg}$ versus $9.7 \pm 0.7 \mathrm{~kg}$ and 9.4 $\pm 1.4 \mathrm{~kg}$, respectively; $p<0.001)$, longer $(81 \pm 3.4 \mathrm{~cm}$ versus $79 \pm 2.7 \mathrm{~cm}$ and $77 \pm 4.9 \mathrm{~cm}$, respectively; $p<0.001)$, and had a greater OFC than boys in B and C $(49 \pm 1.7 \mathrm{~cm}$ versus $48 \pm 2.0 \mathrm{~cm}$ and $48 \pm 1.5 \mathrm{~cm}$, respectively; $p<0.01)$ and girls in A (weight, $10.1 \pm 1.2 \mathrm{~kg}$; length, $79 \pm 2.2 \mathrm{~cm}$; OFC, $48 \pm$ $1.3 \mathrm{~cm} ; p<0.05)$.

In girls, no differences were detected in weight, length, or OFC among the groups. At $18 \mathrm{mo}$, weight $(10.1 \pm 1.2 \mathrm{~kg}, 10.2$ $\pm 1.2 \mathrm{~kg}, 10.1 \pm 1.5 \mathrm{~kg}$, respectively), length $(79 \pm 2.2 \mathrm{~cm}$, $79 \pm 3.2 \mathrm{~cm}, 78 \pm 3.5 \mathrm{~cm}$, respectively), and OFC (48 \pm 1.3
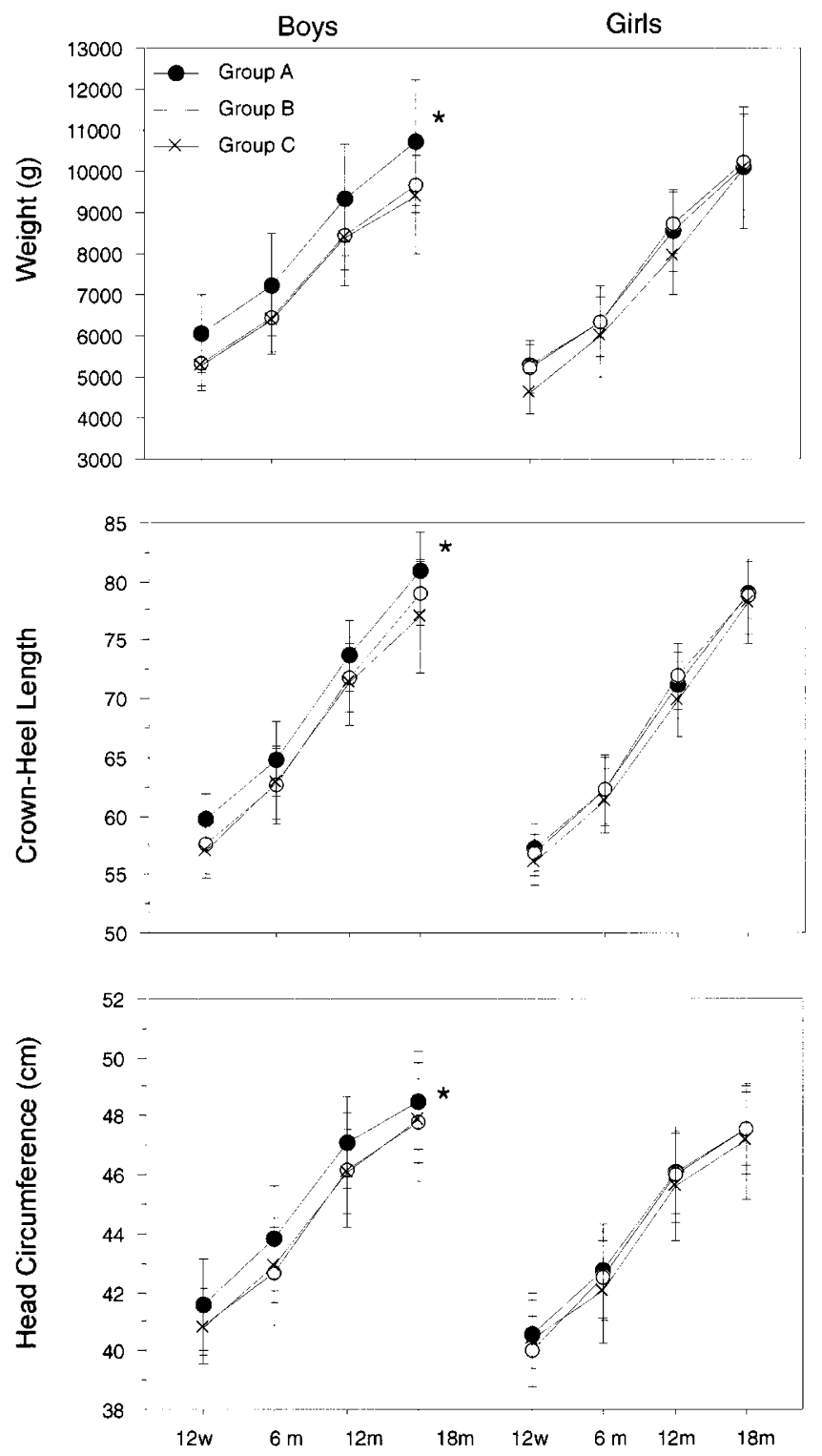

Fig. 1. Body weight, crown-heel length, and OFC in the three study groups. Results are mean $\pm \mathrm{SD}$. Closed circles, open circles, and crosses indicate infants fed the preterm (A), term (B), and preterm followed by term (C) formulas, respectively. Data were analyzed using ANOVA. ${ }^{*} p<0.0001$ for differences between $\mathrm{A}$ and $\mathrm{B} / \mathrm{C}$. 
$\mathrm{cm}, 48 \pm 1.2 \mathrm{~cm}, 47 \pm 2.0 \mathrm{~cm}$, respectively) were similar in groups $\mathrm{A}, \mathrm{B}$, and $\mathrm{C}$.

The SD scores for the study groups are presented in Figure 2. $Z$ score for weight fell in boys $(p<0.001)$ but remained stable (groups A and B) or increased (group $\mathrm{C} ; p<0.001$ ) in girls. $Z$ scores for body length remained stable in boys but increased in girls $(p<0.01)$. In boys and girls, $z$ scores for OFC decreased during the study $(p<0.0001)$.

The MDI and PDI scores are presented in Table 3. No overall differences were noted in MDI or PDI among the groups or among boys in group A compared with boys in groups $\mathrm{B}$ or $\mathrm{C}$, or among girls in group $\mathrm{A}$ compared with groups $\mathrm{B}$ or $\mathrm{C}$. However, MDI scores (mean difference, $6.0 ; p$ $<0.01$ ) were less whereas PDI scores tended to be less (mean difference, $3.0 ; p=0.10$ ) in boys than girls. This primarily
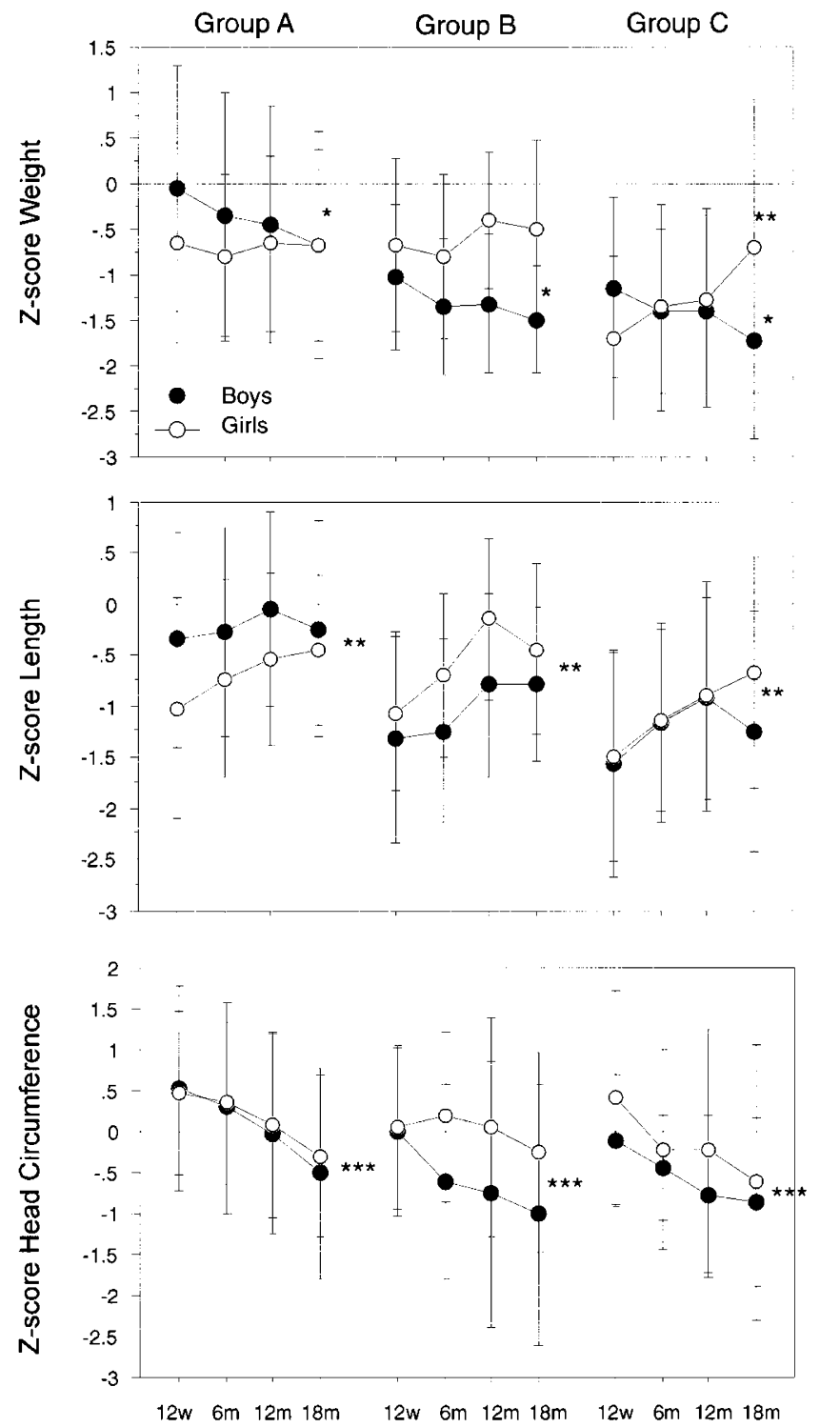

Fig. 2. $Z$ scores in the three study groups. Results are mean \pm SD. Closed circles and open circles are boys and girls, respectively. Data were analyzed using ANOVA. ${ }^{*} p<0.05$ for differences between $12 \mathrm{wk}$ and 6 mo in boys; ${ }^{* *} p<0.05$ for differences between $12 \mathrm{wk}$ and 6 mo in girls; *** $p<0.01$ for differences between $12 \mathrm{wk}$ and 6 mo in boys and girls.
Table 3. Bayley scores in study infants

\begin{tabular}{ccrr}
\hline Test & A & B & \multicolumn{1}{c}{ C } \\
\hline MDI & & & \\
All & $102 \pm 14$ & $103 \pm 14$ & $102 \pm 11$ \\
Girls & $103 \pm 14$ & $107 \pm 14$ & $104 \pm 12$ \\
Boys & $100 \pm 15$ & $97 \pm 11$ & $99 \pm 11$ \\
PDI & & & \\
All & $102 \pm 8$ & $103 \pm 9$ & $99 \pm 8$ \\
Girls & $103 \pm 8$ & $105 \pm 9$ & $98 \pm 8$ \\
Boys & $101 \pm 7$ & $101 \pm 7$ & $101 \pm 7$ \\
\hline
\end{tabular}

Values are reported as mean $\pm \mathrm{SD}$. A, B, and C represent infants fed the preterm formula, the term formula, and the preterm + the term formula, respectively.

reflected differences in group $\mathrm{B}$, in which 10- and 4-point differences were noted in MDI and PDI between the sexes $(p<$ $0.05)$.

\section{DISCUSSION}

The importance of diet in promoting normal growth is without question, and a direct relationship between diet and growth appears self-evident. However, the effects of diet on growth may be confounded by dietary factors outside experimental control. In this study, in which infants were randomized to one of three diets at hospital discharge (approximately $36 \mathrm{wk}$ gestation) weaning was introduced at approximately 2 mo corrected age $(15,16)$. The growth difference established at 2-3 mo was maintained at 18 mo, suggesting that weaning had little effect on later growth.

Examining growth using standardized $z$ scores appears to present a different picture. Between $12 \mathrm{wk}$ and $18 \mathrm{mo}, z$ scores for weight fell in boys but remained stable or increased in girls. $Z$ scores for length remained stable in boys but increased in girls. In terms of weight gain, growth faltering was apparent in boys but not in girls. In terms of length gain, catch-up was apparent in girls but not in boys. These findings suggest that as weaning progressed, dietary intake more adequately met the needs of girls than boys.

$Z$ scores for OFC fell in both sexes. This is difficult to interpret because flattening, a common problem during early life in preterm infants, may falsely increase OFC and, therefore, $z$ score $(2,18)$. In this study, $z$ scores for OFC were greater than those for weight or length, suggesting falsely elevated OFC determination at $12 \mathrm{wk}$. As infants grew, $z$ scores for OFC fell, so scores for OFC, weight, and length were similar at 18 mo. Thus, with age the skull may assume a more circular shape and $z$ score a more appropriate centile position.

Although boys in group A were $1.0 \mathrm{~kg}$ heavier and $2.0 \mathrm{~cm}$ longer and had a $1.0 \mathrm{~cm}$ greater OFC than boys in groups $\mathrm{B}$ and $\mathrm{C}(p<0.0001)$, no differences were detected in MDI of PDI among the groups. Boys in group A were also $0.7 \mathrm{~kg}$ heavier and $2 \mathrm{~cm}$ longer and had a $2.0 \mathrm{~cm}$ greater $\mathrm{OFC}$ than girls in group A $(p<0.01)$, but no differences were noted in MDI or PDI. This may, in part, reflect inadequate power because of a small sample size.

For comparisons among the treatment groups, infants were not initially stratified according to sex. The effects of diet on growth were only noted in boys. A larger sample size would 
have been needed to have enough power to detect a statistically significant difference. However, PDI scores were identical (101 \pm 7 versus $101 \pm 7$ versus $101 \pm 7$ ), whereas MDI scores were similar $(100 \pm 15$ versus $97 \pm 11$ versus $99 \pm 11)$ in boys fed either the preterm or term formula. Increased numbers are unlikely to show any difference in PDI. Whether a statistical difference of 1-3 points in MDI is clinically relevant is, perhaps, debatable.

Other explanations are possible. Brain growth is rapid during the last trimester and the first $2 \mathrm{y}$ of life, a time when even minor insults may have significant effects $(19,20)$. However, not all parts of the brain are developing at the same rate and, therefore, are not equally vulnerable (19). In effect, global measures of function such as the Bayley assessment may not be sensitive enough to detect minor or focal differences in developmental outcome (21).

The relationship between diet and behavior is also not clear-cut (21-24). Human field studies in infants show that the dietary rehabilitation alone is not adequate (25) and that close attention must be paid to social and environmental factors that "deprive infants of normal, parental, emotional, and educative care." Thus, although diet may directly affect somatic growth, the effects on brain growth and behavior may only be achieved when environmental circumstances are supportive.

Nonetheless, Lucas et al. (10, 12-14) suggest that even short periods of dietary intervention have long-term effects on behavior. The same studies show that maternal choice, social, and environmental factors are also important determinants of behavior $(26,27)$. It is, therefore, difficult to disentangle the effects of diet from nondietary factors when assessing development in these infants $(21,23,24)$. Data from this study indicate that sex is also an important confounding variable, further confusing the issue.

Nonetheless, the results of this study are important. The data show that early diet can have long-term positive effects on growth in preterm boys. However, boys fed a preterm infant formula still remain growth-retarded at $18 \mathrm{mo}$, the reasons for which are not clear but may, in part, be related to weaning. Little is known about weaning in preterm infants. Future studies must more closely examine the effects of weaning on growth and the extent to which it does or does not meet requirements in these rapidly growing infants.

This study was unable to show that better growth led to better development. However, MDI and PDI scores were close to normal suggesting an overall improvement in care in these high-risk infants. It is a concern that boys who only received the term formula (group B) had the lowest OFC, OFC $z$ score, and MDI. Because of the small sample size, our data cannot exclude the possibility that infants fed a term formula after hospital discharge are developmentally at risk when compared with those fed a preterm formula. Further studies are needed to examine this issue.

Acknowledgment. The authors thank the nursing and medical staff on the Special Care Baby Units of the Royal Victoria
Infirmary and Ashington General Hospital, without whose support this study would not have been possible.

\section{REFERENCES}

1. Ernst JA, Bull MJ, Rickard KA, Brady MS, Lemons JA 1990 Growth outcome and feeding practices of the very low birth weight infant (less than 1500 grams) within the first year of life. J Pediatr 117(suppl):S156-S166

2. Casey PH, Kraemer HC, Bernbaum J, Tyson JE, Sells JC, Yogman MW, Bauer CR 1990 Growth patterns of low birth weight preterm infants: a longitudinal analysis of a large, varied sample. J Pediatr 117:298-307

3. Fitzhardinge PM, Inwood S 1989 Long-term growth in small-for-date children. Acta Paediatr Scand Suppl 349:27-33

4. Fenton TR, McMillan DD, Sauve RS 1990 Nutrition and growth analysis of very low birth weight infants. Pediatrics 86:378-383

5. Kitchen WH, Doyle LW, Ford GW, Callanan C, Rickards AL, Kelly E 1992 Very low birth weight and growth to age 8 years. II: head dimensions and intelligence. Am J Dis Child 146:46-50

6. Ehrenkranz RA, Younes N, Lemons JA, Fanaroff AA, Donovan EF, Wright LL, Katsikiotis V, Tyson JE, Oh W, Shankaran S, Bauer CR, Korones SB, Stoll BJ, Stevenson DK, Papile LA 1999 Longitudinal growth of hospitalised very low birth weight infants. Pediatrics 104:280-289

7. Gorga D, Stern FM, Ross G 1985 Trends in neuromotor behaviour of preterm and fullterm infants in the first year of life: a preliminary report. Dev Med Child Neurol 27:756-766

8. Georgieff MK, Hoffman JS, Pereira GR, Bernbaum J, Hoffman-Williamson M 1985 Effect of neonatal caloric deprivation on head growth and 1-year developmental status in preterm infants. J Pediatr 107:581-587

9. Hack M, Breslau N, Weissman B, Aram D, Klein N, Borawski E 1991 Effect of very low birth weight and subnormal head size on cognitive abilities at school age. N Engl J Med 325:231-237

10. Lucas A, Gore SM, Cole TJ, Bamford MF, Dossetor JF, Barr I, Dicarlo L, Cork S, Lucas PJ 1984 Multicentre trial on feeding low birth weight infants: effects of diet on early growth. Arch Dis Child 59:722-730

11. Georgieff MK, Mills MM, Lindeke L, Iverson S, Johnson DE, Thompson TR 1989 Changes in nutritional management and outcome of very-low-birth-weight infants. Am J Dis Child 143:82-85

12. Lucas A, Morley R, Cole TJ, Gore SM, Davis JA, Bamford MF, Dossetor JF 1989 Early diet in preterm babies and developmental status in infancy. Arch Dis Child 64:1570-1578

13. Lucas A, Morley R, Cole TJ, Gore SM, Lucas PJ, Crowle P, Pearse R, Boon AJ, Powell R 1990 Early diet in preterm babies and developmental status at 18 months. Lancet 335:1477-1481

14. Lucas A, Bishop NJ, King FJ, Cole TJ 1992 Randomised trial of nutrition for preterm infants after discharge. Arch Dis Child 67:324-327

15. Cooke RJ, Griffin IJ, McCormick K, Wells JCK, Smith JS, Robinson SJ, Leighton M 1998 Feeding preterm infants after hospital discharge: effect of dietary manipulation on nutrient intake and growth. Pediatr Res 43:355-360

16. Cooke RJ, McCormick K, Griffin IJ, Embleton N, Faulkner K, Wells JC, Rawlings DC 1999 Feeding preterm infants after hospital discharge: effect of diet on body composition. Pediatr Res 46:461-464

17. Cole TJ, Freeman JV, Preece MA 1998 British 1990 growth reference centiles for weight, height, body mass index and head circumference fitted by maximum penalised likelihood. Stat Med 17:407-429

18. Baum JD, Searls D 1971 Head shape and size of pre-term low-birthweight infants Dev Med Child Neurol 13:576-581

19. Dobbing J 1981 The later development of the brain and its vulnerability. In: Davis JA, Dobbing J (eds) Scientific Foundations of Pediatrics. University Park Press, Baltimore, pp $744-758$

20. Dobbing J 1989 Vulnerable periods in developing brain. In: Dobbing JJ (ed) Brain, Behaviour, and Iron in the Infant Diet. Springer-Verlag, London, pp 1-26

21. Singer LT 1997 Methodological considerations in longitudinal studies of infant risk In: Dobbing J (ed) Developing Brain and Behaviour: The Role of Lipids in Infant Formula. Academic Press, San Diego, pp 209-252

22. Dobbing J 1990 Brain, Behaviour, and Iron in Infant Diet. Springer-Verlag, London

23. Wainwright PE, Ward GR 1997 Early nutrition and behaviour: a conceptual framework for critical analysis of research. In: Dobbing J (ed) Developing Brain and Behaviour: The Role of Lipids in Infant Formula. Academic Press, San Diego, pp 387-426

24. Thureen PJ, Phillips RE, DeMarie MP, Hoffenberg A, Bronstein MN, Spedale SB, Hay Jr WW 1997 Technical and methodologic considerations for performance of indirect calorimetry in ventilated and nonventilated preterm infants. Crit Care Med 25:171-180

25. Grantham-McGregor S 1987 Field studies in early nutrition and later achievement. In: Dobbing J (ed) Early Nutrition and Later Achievement. Academic Press, London, pp $128-174$

26. Morley R, Cole TJ, Powell R, Lucas A 1988 Mother's choice to provide breast milk and developmental outcome. Arch Dis Child 63:1382-1385

27. Lucas A, Cole TJ, Morley R, Lucas PJ, Davis JA, Bamford MF, Crowle P, Dossetor JF, Pearse R, Boon A 1988 Factors associated with maternal choice to provide breast milk for low birth weight infants. Arch Dis Child 63:48-52 